\title{
The Roles of Hope and Growth Mind-Set in the Relationship between Mothers' Parenting Stress and Children's Well-being
}

Chang Seek Lee*

Department of Child and Adolescent Welfare, Hanseo University, 31962, Korea; lee1246@hanmail.net

\begin{abstract}
Objectives: To clarify the roles of hope and growth mind-set in the relationship between stress from child-rearing and children's well-being. Methods/Statistical analysis: In this study, SPSS Win 21.0 was used to calculate the reliability analyses, descriptive statistics, and correlation analyses. SPSS MACRO was applied to calculate dual mediating effect and verify bootstrapping. Findings: The results showed that children's well-being is negatively and directly influenced by parenting stress in mothers but also identifies how to improve children's well-being by increasing hope in mothers and enhancing their growth mind-sets, specifically confirming the double mediating effects of hope and growth mind-set in the relationship between parenting stress and the children's well-being. Improvements/Applications: It will be used to improve children's well-being by incorporating both parental hope and mothers' growth mind-sets in any plans.
\end{abstract}

Keywords: Double Mediating Effect, Growth Mind-Set, Hope, Parenting Stress, Wellbeing

\section{Introduction}

People cannot live without hope, and it has been a dream of many in the past. However was the first to develop a concept of hope that could be measured. In 1 defined hope as positive inspiration in organized interactions between successful agency and pathways. In said that hope comprised pathway thinking for finding paths to achieving goals and agency thinking for pursuing the goals In developed pathway thinking and agency thinking as measurable variables.

Many studies have clarified how hope has been applied in various areas based on hope scale. In insisted that humans need hope because they face problematic or difficult situations, and hope gets us through these situations. In addition, those with high hope tend to find more alternatives when they face obstacles'; they tend to tell themselves, "This will be fine" or "I can do it" and use agency thinking in constructive directions, Accordingly, hope plays the important role of inspiring us to overcome obstacles or difficulties, and it performs this same role in the relationship between parents' stress and children's well-being.
In 1 suggested a growth mind-set as a variable for predicting success in interpersonal relationships and emotional and physical health in various fields including academic studies. An individual's mind-set is his or her beliefs about him-/herself and his/her most basic qualities] and it can be classified as growth or fixed. Growth mind-sets reflect people's beliefs that they can change if they make the effort and learn their beliefs that intelligence, ability, and inspiration are flexible; these beliefs are connected with both incremental theory. In contrast, fixed mind-sets reflect the opposite conceptual beliefs, that improving intelligence is not possible.

$\operatorname{In} 1$ reports that most adults tend to have fixed mindsetsf. Belief in the ability to improve intelligence and reality can inspire and inform people's successes and failures. However, people with fixed mind-sets tend to avoid challenges out of fear of appearing incompetent, and they tend to be less flexible when they face obstacles. Those with growth mind-sets, in contrast, tend to be highly flexible when they face obstacles and to regard challenges as opportunities to learn; for these individuals, obstacles are opportunities for learning rather than self-criticism. 
In previous studies, instructors with fixed mind-sets had no influence on their students' abilities, whereas instructors with growth mind-sets had high-achieving students. This is because students with growth mindsets believe that they can develop their intelligence under the influence of their instructors, and thus, they focus on learning, believe in their efforts, and flexibly face their obstacles $^{8}$. In the context of this study, a growth mind-set is expected to reduce mothers' stress and play a positive role in increasing children's well-being.

Parenting stress is recognized as normal for parents? with mothers' parenting stress referring to the general stress of fulfilling the roles and burdens of mothersto The problem is that mothers' parenting stress can lead to negative child-raising behaviors and both directly and indirectly influence children's development. In other words, stress in mothers is reflected in children's reactions and behaviors, usually with negative effects from harsh or critical child-rearing attitudes 1 . Furthermore, stress from child-rearing negatively influences mothers' subjective well-being 1 , particularly for mothers whose children are not yet attending school compared with mothers of school-age children. It has also been reported that their well-being is lown. Therefore, there is a need for academic interest in mothers' parenting stress and for studies on relieving this stress in order to promote the healthy development of infants and children.

Well-being is used to refer to life satisfaction, happiness, and quality, and it reflects this current life satisfaction as a cognitive factor of subjective happiness In addition, well-being is divided into subjective, which focuses on self-evaluation of happiness from a hedonistic

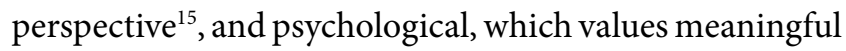
lived related to individual development and maturity from the perspective of happiness 1 . Well-being relates to leading meaningful lives with desirable relationships throughout life, not merely temporary human emotions

For infants, happiness can be assessed by their relationships with others around them in daily life, personal satisfaction and pleasure, positive adjustments to changes, and harmonization, and well-being is especially important in early childhood. Infants' well-being is considered happiness in their brains, and it develops in them the ability to solve issues they might confront in the futuref recognize their control over their lives, and pursue their own happiness 19,20 .

One of the important factors in well-being is relationships with others, and this is true for infants as well. Infants tend to feel happiness and satisfaction when they coexist with loved ones in mutually beneficial communion and intimacy, and their relationships with their mothers play an important role. The happier the mothers, the happier the children ${ }^{2}$. Conversely, as mothers feel more parenting stress, infants' cognition of their happiness decreases. Protecting mothers from stress in child-rearing is very important for children's healthy development and growth.

The above sections discuss four variables: mothers' parenting stress, hope as a predictor of success, growth mind-set, and well-being; these variables are not independent or dependent but interact with each other. For this study, however, and based on research findings that mothers' parenting stress negatively influences children's well-being ${ }^{12}$, parenting stress was set as the independent variable, and the biggest goal in life, children's well-being, was set as the dependent variable. The study then aimed to explore whether it was feasible for hope and a growth mind-set to both serve as mediators.

Specifically, the objectives of this study were to clarify the roles of hope and growth mind-set in the relationship between stress from child-rearing and children's wellbeing with regard to mothers of school-age children who attended education institutions and to develop a plan to improve children's well-being by reducing mothers' stress.

\section{Methods}

\subsection{Research Model}

Based on previous studies, the research model shown in Figure 1 was established, showing hope and growth mind-set as double mediators in the relationship between mothers' parenting stress and children's well-being.

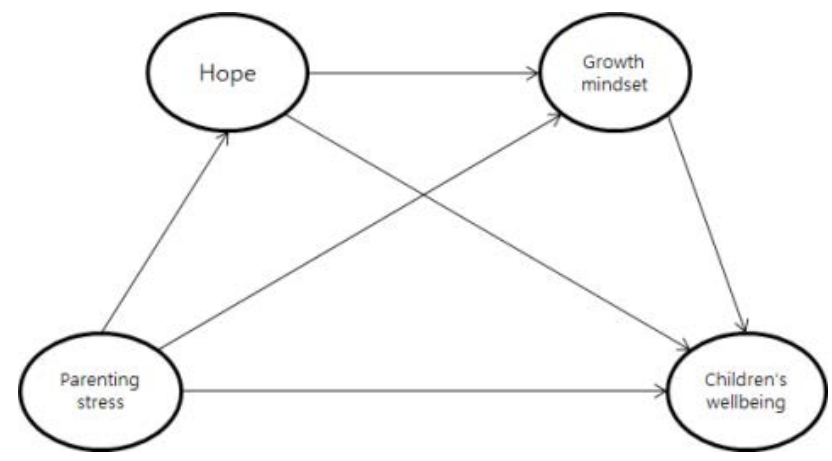

Figure 1. Research model. 


\subsection{Participants and Data Collection}

The study participants were mothers of children who attended day care centers and kindergartens who were selected through purposive sampling; the total number of mothers was 290. Data were collected after visits to each facility to explain to each chairperson the purpose of the survey; then the surveys were distributed through the children and collected from them or given directly to the mothers during individual meetings.

The women's average age was 34.41 years, and $59.8 \%$ lived in small or medium cities; close to half, $40.2 \%$, of participants resided in farming and fishing villages. For education level, the most women, $55.8 \%$, were college graduates, and $37.2 \%$ were high school graduates. For employment, $28.1 \%$ of the mothers were managers, office workers, or public servants, followed by $24.4 \%$ who worked in sales and $18.9 \%$ who were self-employed. For economic status, most of the women, $71.3 \%$, rated their status as "normal."

\subsection{Survey Tools}

The research tools discussed below were used to assess parenting stress, children's well-being, hope, and growth mind-set. The details are as follows.

\subsubsection{Parenting Stress}

To measure parenting stress, this study used the Parenting Stress Index by as translated by questions along three subscales: parents, parents and children, and child-rearing; specific items relate to how parents de-stress (parents), dysfunctional interactions with children (parents and children), and children's difficult temperaments (child-rearing) in terms of parents' stress sources and levels; parents rate each item on a five-point Likert scale where higher scores indicate higher stress levels. Reliability of the PSI (Cronbach's $\alpha$ ) is as high as .914.

\subsubsection{Children's Well-Being}

To assess the children's well-being, the study used the children's happiness scale that was developed and verified by 3 . The scale requires parents to rate the happiness of their school-age children and comprises a total of 36 questions in nine areas. These items are also rated on a five-point Likert scale, with higher scores reflecting children's greater well-being as assessed by the parents. Cronbach's a for the scale is .949 .

\subsubsection{Hope}

To measure hope, the study used the scale developed by and translated into the K-DHS and verified by ${ }^{2}$. This scale comprises eight questions that measure agency thinking (establishing goals) and pathway thinking (achieving goals). The eight items are rated on a five-point Likert scale where a higher score indicates greater happiness. Cronbach's $\alpha$ is .776, which is appropriate.

\subsubsection{Growth Mind-Set}

This researcher measured growth mind-set by translating a scale that was developed by and used by ${ }^{2}$. The scale comprised 20 questions rated on a five-point Likert scale with higher scores reflecting a greater growth mind-set. This scale's Cronbach's $\alpha$ is .821.

\subsection{Data Analysis}

In this study, SPSS Win 21.0 and SPSS MACRO were used to calculate the reliability analyses, descriptive statistics, correlation analyses, and bootstrapping.

\section{Results}

\subsection{Correlations among the Main Variables}

According to the correlation analyses as shown in Table 1, parenting stress was negatively correlated with hope, growth

Table 1. Correlation coefficient and descriptive statistics of main variables

\begin{tabular}{lccccc}
\hline & 1 & 2 & 3 & M & SD \\
\hline 1. Parenting stress & 1 & & & 2.5138 & 0.46792 \\
2. Hope & $-.420^{\star *}$ & 1 & & 2.8888 & 0.37069 \\
3. Growth mind-set & $-.483^{\star *}$ & $.314^{\star *}$ & 1 & 3.4958 & 0.39702 \\
4. Children's wellbeing & $-.551^{\star *}$ & $.375^{\star *}$ & $.392^{\star *}$ & 3.59 & 0.5069 \\
\hline${ }^{* *} \mathrm{p}<.01$ & & & & &
\end{tabular}


mind-set, and children's well-being, but hope, growth mindset, and children's well-being were positively correlated. The frequency analyses showed that mother's parenting stress was lower than the median, and hope, growth mind-set, and children's well-being were higher than the median.

\subsection{Coefficients in Each Path}

Figure 2 presents the total effects of parenting stress on children's well-being $(-.5954, \mathrm{p}<.001)$. In Figure 3 displays the coefficients in each path to verify the double mediating effects, and all path coefficients were statistically significant. Parenting stress negatively influenced hope $(-.3319, \mathrm{p}<.001)$, growth mind-set $(-.3614, \mathrm{p}<.001)$, and children's well-being $(-.4509, \mathrm{p}<.001)$. Hope positively influenced growth mind-set $(.1437, \mathrm{p}<.05)$ and children's well-being $(.2125, \mathrm{p}<.01)$, and growth mind-set positively influenced children's well-being $(.1807, \mathrm{p}<.05)$.

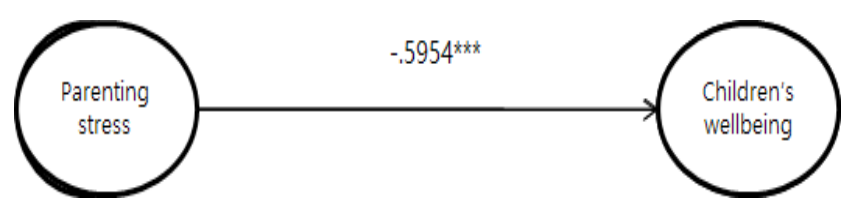

Figure 2. Total effect of parenting stress and children's wellbeing.

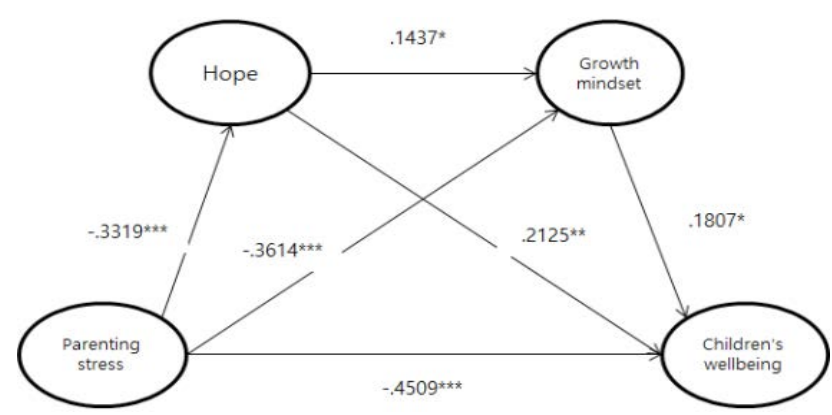

Figure 3. Paths of four variables.

\subsection{Verification of Double Mediating Effect} This study used bootstrapping in SPSS MACRO to verify the double mediating effects of growth mind-set and hope in the relationship between parenting stress in mothers of schoolage children and their children's well-being. In ${ }^{26,27}$ mediating effect analyses were limited in that they could not reflect measurement error or verify precise mediating models 2 . Therefore ${ }^{2}$ and ${ }^{2}$ suggested bootstrapping as an alternative.

Thus, this study designated bootstrapping at 5.000 to analyze the double mediating effects and set the confidence interval (CI) at 95\%. The analysis showed that the total mediating effect, as shown in Table 2, was -.1445 (range: -.2284 to -.0676 ). Because 0 did not exist at the $95 \%$ CI, the total effect was significant. In addition, regarding the simple mediating effects, the effect on the parenting stress->hope$>$ children's well-being relationship was found to be -.0705 (range: -.1327 to -.0249), and the parenting stress -> hope -> growth mind-set $->$ children's well-being relationship effect was -.0086 (range: - .1244 to -.0120). Again, because 0 did not exist at the $95 \% \mathrm{CI}$, the individual simple mediating effect was also significant. In addition, the results for verifying the double mediating effects of the parenting stress->growth mind-set->children's well-being relationship, the effect was -.0653 (range: -.1244 to -.0120 ). Because there was no 0 at the $95 \% \mathrm{CI}$, the double mediating effect was also confirmed.

\section{Discussion and conclusion}

Parenting stress is inevitable in the course of raising children; because parenting stress and children's well-being are negatively correlated, plans for improving children's well-being is very important for their healthy growth and development. In order to develop such a plan, this study verified the double mediating effects-compared with simple or multiple mediation-of hope and growth mindset in the relationship between parenting stress and the wellbeing of children who attended child education institutions.

This study's results confirmed that children's well-being is negatively and directly influenced by parenting stress

Table 2. CDouble mediating effect of hope and growth mind-set

\begin{tabular}{lcccc}
\hline Classification & \multicolumn{4}{c}{ Mediating effects } \\
\hline \multicolumn{1}{c}{ B } & \multicolumn{1}{c}{ S.E. } & BC 95\% CI \\
Parenting stress->Hope->Children's & -.0705 & .0271 & $-.1327 \sim-.0249$ \\
$\begin{array}{l}\text { wellbeing } \\
\text { Parenting stress -> Hope -> Growth } \\
\text { mind-set -> Children's wellbeing }\end{array}$ & -.0086 & .0056 & $-.0243 \sim-.0010$ \\
$\begin{array}{l}\text { Parenting stress-> Growth mind-set- } \\
\text { >Children's wellbeing }\end{array}$ & -.0653 & .0279 & $-.1244 \sim-.0120$ \\
Total Indirect Effect & -.1445 & .0414 & $-.2284 \sim-.0676$ \\
\hline
\end{tabular}


in mothers but also identifies how to improve children's well-being by increasing hope in mothers and enhancing their growth mind-sets, specifically confirming the double mediating effects of hope and growth mind-set in the relationship between parenting stress and the children's well-being. It is thus feasible to improve children's wellbeing by incorporating both parental hope and mothers' growth mind-sets in any plans. These results are meaningful in that they clarify these double mediating effects and lay the groundwork for future follow-up studies.

\section{Acknowledgment}

This paper was undertaken with the support of a research grant in 2016 from Hanseo University.

\section{References}

1. Snyder CR. The psychology of hope: You can get there from here. Simon and Schuster; 1994. p. 428.

2. Snyder CR, Harris C, Anderson JR, Holleran SA, Irving LM, Sigmon ST, Harney P. The will and the ways: development and validation of an individual-differences measure of hope. Journal of Personality and Social Psychology. 1991; 60(4):570-85.

3. Snyder CR, Pointe ABL, Crowson JJ, Early S. Preferences of high-and low-hope people for self-referential input. Cognition and Emotion. 1998; 12(6):807-23.

4. Snyder CR, Parenteau SC, Shorey HS, Kahle KE, Berg C. Hope as the underlying process in the psychotherapeutic change process. International Gestalt Journal. 2002; 25(2):11-9.

5. Irving LM, Telfer L, Blake DD. Hope, coping, and social support in combat-related posttraumatic stress disorder. Journal of Traumatic Stress. 1997; 10(3):465-79.

6. Dweck CS. Self-Theories: Their role in motivation, personality and development. Philadelphia: Taylor and Francis/ Psychology Press: New York; 2000.

7. Lee CS, Hwang YK. The structural relationships between social support, emotional intelligence, self-esteem, and hope in rural elementary school students. Indian Journal of Science and Technology. 2016; 9(26):1-6.

8. Dweck CS. Mindset: The new psychology of success. RHUS: New York; 2007.

9. Abidin RR. Parenting Stress Index (PSI). Charlottesville, VA: Pediatric Psychology Press: New York; 1990.

10. Kim KH, Kang HG. Development of parenting stress scale. Family and Environment Research. 1997; 35(5):141-50.

11. Crnic KA, Greenberg MT. Minor parenting stresses with young children. Child development. 1990; 61(5):1628-37.

12. Park SS. A study on the parenting stress of the dual-earner mothers and fathers [Master's thesis]. South Korea, Cheongju University; 2004.
13. Skok A, Harvey D, Reddihough D. Perceived stress, perceived social support, and wellbeing among mothers of school-aged children with cerebral palsy. Journal of Intellectual and Developmental Disability. 2006; 31(1):53-7.

14. Pavot W, Diener E. The satisfaction with life scale and the emerging construct of life satisfaction. The Journal of Positive Psychology. 2008; 3(2):137-52.

15. Diener E. Subjective well-being: The science of happiness and a proposal for a national index. American Psychological Association. 2000; 55(1):34-43.

16. King LA, Napa CK. What makes a life good? Journal of personality and social psychology. 1998; 75(1):156-65.

17. Lee CS, Hwang YK. The effects of hope, emotional intelligence, and stress on the self-esteem of rural elementary school students in Korea: The mediating effect of social support. Indian Journal of Science and Technology. 2016; 9(26):1-7.

18. Seligman M E. Learned optimism: How to change your mind and your life. Vintage; 2011. p. 319.

19. Shahar TB. Happier: Learn the secrets to daily joy and lasting fulfillment. McGraw-Hill Companies: New York; 2007.

20. Lyubomirsky S. The how of happiness: A scientific approach to getting the life you want. Penguin; 2008.

21. Lee CS, Hwang YK. Structural relationship among social support, hope, stress and emotional intelligence of rural elementary school students in Korea: The mediating effect of self-esteem. Indian Journal of Science and Technology. 2016; 9(26):1-7.

22. Seo HY. A study on the adaptation of mothers of children with disabilities and social support [Master's thesis]. Korea, Cheongju University. Yeonsei University; 1991.

23. Lee EJ. A study on development of a happiness scale for young children: based on early childhood educational institution [Doctoral thesis]. Seoul, Korea, Sungkyungkwan University; 2010.

24. Choi YH, Lee HK, Lee DG. Validation of the Korean version of Snyder's dispositional hope scale. Korean Psychological Association. 2008; 22(2):1-16.

25. Ayers JC. Encouraging a growth mindset [Doctoral thesis]. Washington, USA, The Evergreen State College; 2015.

26. Baron RM, Kenny DA. The moderator-mediator-variable distinction in social psychological research. Journal of Personality and Social Psychology. 1986; 51(6):1173-83.

27. Sobel ME. Asymptotic confidence intervals for indirect effects in structural equations models. In Leinhart S editors. Sociological Methodology, San Francisco: Jossey-Bass. 1982; 13:290-312.

28. Hayes AF, Preacher KJ, Myers TA. Mediation and the estimation of indirect effects in political communication research. In Bucy EP, Holbert RL editors. Sourcebook for political communication research: Methods, measures, and analytical techniques. New York: Routledge; 2010.

29. Preacher KJ, Hayes AF. SPSS and SAS procedures for estimating indirect effects in simple mediation models. Behavior Research Methods, Instruments, and Computers. 2004; 36(4):717-31. 